\title{
Posterior reversible encephalopathy syndrome in a woman with focal segmental glomerulosclerosis
}

This article was published in the following Dove Press journal:

Neuropsychiatric Disease and Treatment

21 April 2015

Number of times this article has been viewed

\author{
Mudit Chowdhary' \\ Ahmad A Kabbani' \\ Devon Tobey' \\ Thomas D Hope ${ }^{2}$ \\ 'Department of Internal Medicine, \\ Mercer University School of Medicine, \\ Macon, GA, USA; ${ }^{2}$ Department of \\ Neurology, Mercer University School \\ of Medicine, Macon, GA, USA
}

\begin{abstract}
Posterior reversible encephalopathy syndrome (PRES) is a rare syndrome characterized by reversible vasogenic edema in the posterior hemispheres. PRES is most often attributed to primary hypertension, pre-eclampsia, and neurotoxicity secondary to immunosuppressants such as cyclosporine. Renal disease is an infrequent cause of PRES with a majority of cases occurring in adults with complete renal failure or in pediatric cases with underlying renal parenchymal disease and concurrent immunosuppressive therapy. Typical symptoms include seizure, headache, altered mental status, and visual disturbances. PRES is rarely associated with cerebral hemorrhage, and even less so with subarachnoid bleeds. Herein we report on a 25-year-old female with focal segmental glomerulosclerosis who developed PRES. The patient's presentation was more severe as she presented with seizure, nephrotic syndrome, and subarachnoid hemorrhage. Computed tomography and magnetic resonance imaging with concurrent symptoms led us to the final diagnosis. The patient was treated with antihypertensives, diuretics, and corticosteroids and follow-up imaging revealed resolution of PRES. Our case illustrates that underlying kidney disease even without immunosuppressive agents should be added to the list of possible causes for PRES. Symptoms are reversible with treatment of underlying cause or offending agent.
\end{abstract}

Keywords: PRES, posterior reversible encephalopathy syndrome, focal segmental glomerulosclerosis, subarachnoid hemorrhage

\section{Introduction}

Reversible posterior leukoencephalopathy syndrome, or posterior reversible encephalopathy syndrome (PRES), is a heterogeneous clinico-radiological syndrome characterized by the sudden onset of headaches, seizures, altered level of consciousness, and visual disturbances. ${ }^{1}$ Neurological imaging typically reveals widespread vasogenic white-matter edema, classically localized to the posterior parietal and occipital lobes. However, the name is a misnomer as this syndrome is not always reversible and edema is not confined to the posterior cerebral cortex. ${ }^{2}$

Though the exact incidence is unknown, PRES has been seen more frequently in females. ${ }^{3}$ PRES can be attributed to a number of acute and chronic conditions, with malignant hypertension, eclampsia, and immunosuppressive medications accounting for the majority of reported cases. ${ }^{4}$ Infrequently, PRES can be associated with nephrotic syndrome, with even fewer cases reported in patients with focal segmental glomerulosclerosis (FSGS).

Here we report a rare case of a young adult female with FSGS who presented with an acute onset seizure with concurrent subarachnoid hemorrhage (SAH) and nephrotic syndrome that was subsequently discovered to be PRES.
Correspondence: Mudit Chowdhary Department of Internal Medicine, Mercer University School of Medicine, 707 Pine Street, Macon, GA 3I20I, USA

Tel +l $47830 \mid 5820$

Fax +I 478 30I 5825

Email mu.chowdhary@gmail.com 


\section{Case presentation}

A 25-year-old woman with a history of FSGS was admitted to our facility with severe headache, double vision, abdominal pain, nausea, vomiting, and altered mental status, with subsequent development of seizure. Prior to the seizure, the patient's systolic blood pressure was severely elevated at $230 \mathrm{mmHg}$. She was not on any immunosuppressive or cytotoxic drugs. Due to her altered mental status, the patient was sedated and intubated and a full review of symptoms was unattainable.

A computed tomography (CT) scan of the head was promptly obtained and it revealed the presence of diffuse vasogenic edema and a small SAH on the cortical surface. Magnetic resonance angiography of the head was performed to determine the source of hemorrhage and no aneurysm, vessel stenosis, or arteriovenous malformation was evident. $\mathrm{CT}$ angiography was not performed due to coexisting chronic renal disease. Magnetic resonance imaging (MRI) of the brain revealed patchy bilateral supratentorial areas of $\mathrm{T} 2$ and fluid-attenuated inversion recovery cortical hyperintensity in the parieto-occipital lobe, which suggested the development of PRES (Figure 1).

The patient's blood pressure stabilized with treatment and she was subsequently extubated. Neurological exam revealed no focal neurological deficits. There were no definite visual field abnormalities and remaining cranial nerves were also intact. The patient displayed good motor and sensory function bilaterally. There were evident signs of nephrotic syndrome including generalized anasarca, but the rest of the exam was otherwise unremarkable.

Laboratory data revealed hemoglobin $(8.2 \mathrm{~g} / \mathrm{dL})$, blood urea nitrogen $(41 \mathrm{mmol} / \mathrm{L})$, creatinine $(2.01 \mathrm{~mol} / \mathrm{L})$, and hypoalbuminemia $(1.9 \mathrm{~g} / \mathrm{dL})$. Urinalysis revealed total urine protein greater than $810 \mathrm{mg} / \mathrm{dL}$, urine protein to creatinine ratio of 9.20, and the presence of hyaline and granular casts. Additionally, the patient's BNP was $923 \mathrm{pg} / \mathrm{mL}$.

The patient was treated with antihypertensive medications (amlodipine, hydralazine) and diuretics to control her blood pressure and volume overload. Additionally, prednisone was started for the underlying FSGS. Over the course of her hospital stay, the patient did not develop additional seizures and regained full consciousness over the course of her admission. Subsequent MRI of the brain 10 days after the seizure onset demonstrated almost complete resolution of the initial edematous change. There was resolution of the nephrotic syndrome after 2 weeks treatment with diuresis and prednisone.

\section{Discussion}

PRES is a rare and complex clinico-radiological syndrome with a reported incidence of only $40 / 100,000(0.04 \%)$ people. ${ }^{5}$
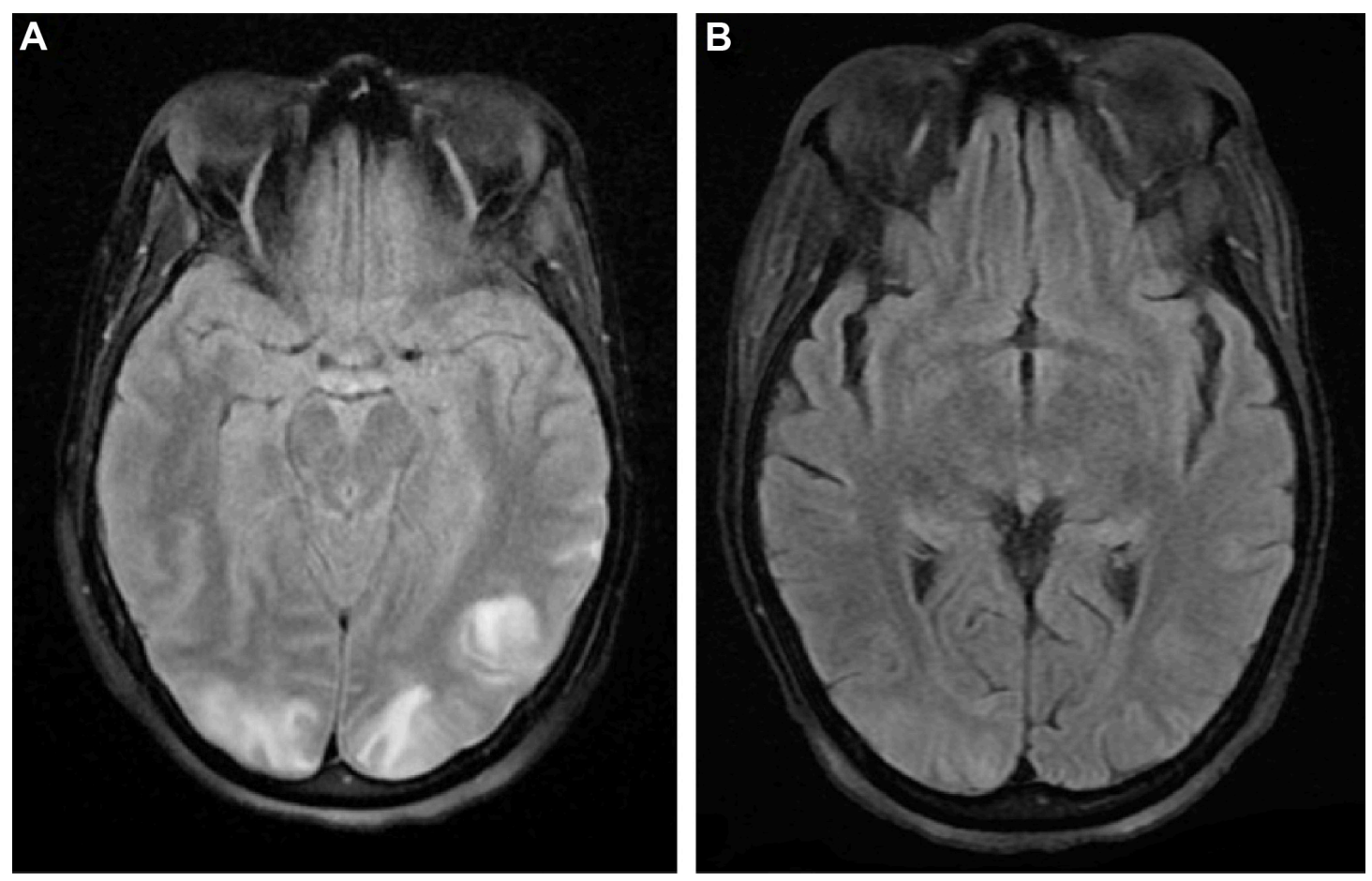

Figure I MRI of the brain on admission revealing (A) cortical hyperintensity in the posterior parieto-occipital lobe, which suggests the presence of PRES; (B) follow-up MRI 10 days after symptom onset showing resolution of PRES.

Abbreviations: MRI, magnetic resonance imaging; PRES, posterior reversible encephalopathy syndrome. 
Females are affected twice as often as males and typically present in the fourth decade of life. ${ }^{6}$ PRES has been attributed to various acute and chronic medical conditions. It most commonly occurs in patients with uncontrolled hypertension, eclampsia, porphyria, or secondary to immunosuppressive and cytotoxic drugs. Renal disease has also been implicated in the development of PRES; however, cases due to nephrotic syndrome are seldom reported. PRES in the setting of FSGS is further rare still, with a literature search finding only two additional cases in the English language (Table 1): 2/3 total cases were males and the median age was $25 .^{7,8}$ All patients presented with seizure and headache; however, the presence of other classical symptoms was variable. The systolic blood pressure ranged from 150 s to 200 s in the three cases. Unlike our scenario, the other cases involved patients who presented with steroid-resistant FSGS. Additionally, SAH was present only in our patient.

The exact pathophysiology of PRES is unknown; however, a number of potential theories exist: most commonly, a precipitating event such as hypertension leads to a loss of cerebral auto regulatory blood flow, leading to vasogenic edema; second, exposure to a causative agent leads to vasospasm and ischemia and subsequent edema; and third, dysfunction or injury to the endothelial cell tight junctions of the blood-brain barrier allows for transudative fluid leakage and resulting cerebral edema. ${ }^{3}$ Patients with FSGS have multiple risk factors for PRES including endothelial dysfunction secondary to cytotoxic drugs such as cyclosporine. Additionally, FSGS is a lesion that leads to nephrotic syndrome. This is primarily due to hypoalbuminemia and proteinuria, resulting in decreased oncotic pressure within vessels and consequently hypovolemia. The subsequent activation of the renin-angiotensin system leads to retention of sodium and water and can lead to secondary hypertension, which in itself is a risk for the development of PRES. Additionally, patients with PRES secondary to FSGS may present at a much younger age than their classical counterparts with essential hypertension as the latter require many years to develop.
Clinical manifestations are acute or sub-acute and highly variable. Patients typically present with the sudden onset of severe headaches, seizures, altered level of consciousness, and visual disturbances. Symptoms usually resolve once the inciting factor is addressed; however, without prompt recognition PRES can progress to cerebral hemorrhage, coma, and death. ${ }^{9}$ Our patient had a similar presentation along with the presence of a SAH. Cerebral hemorrhage is a rare complication of PRES reported in only 5\%-19\% of patients. ${ }^{10}$ Furthermore, PRES is rarely associated with SAH, with most cases developing 1-2 weeks after the onset of hyperdynamic therapy for cerebral vasospasm. ${ }^{11}$ However, this was different in our case in which SAH occurred without hyperdynamic therapy.

Neuroimaging is essential for the diagnosis of PRES. MRI is the imaging of choice and characteristically reveals symmetrical hypo or hyperintense vasogenic white-matter edema, most commonly localized to the posterior temporoparietal-occipital lobes of the cerebral cortex. However, these findings can also be present in other areas of the cerebral hemispheres and the absence of posterior changes does not exclude the diagnosis of PRES. ${ }^{9}$ Follow-up imaging typically shows partially or completely resolved abnormalities suggesting edema rather than infarction.

In conclusion, our case highlights a common pathological mechanism linking FSGS and PRES. It appears that the development of PRES is multi-factorial with the most likely disturbance being secondary hypertension in a patient with renal disease who is not on immunosuppressive therapy. The prognosis is usually benign and typically fully reversible within a period of days to weeks after removal of the inciting factor and control of blood pressure. Clinicians should be aware of the association between renal disease and PRES and keep a high index of suspicion when faced with a patient who presents with severe headache, visual symptoms, confusion, seizures, and classical radiographic changes. Grave consequences including irreversible brain damage and death can occur when clinicians fail to recognize the symptoms;

Table I Review of patients with focal segmental glomerulosclerosis who developed posterior reversible encephalopathy syndrome

\begin{tabular}{|c|c|c|c|c|c|c|c|c|}
\hline \multirow[t]{2}{*}{ Case } & \multirow[t]{2}{*}{ Age/sex } & \multirow[t]{2}{*}{ Location of lesion } & \multirow[t]{2}{*}{ Cyclosporine } & \multicolumn{5}{|c|}{ Clinical presentation } \\
\hline & & & & Seizure & Headache & Visual changes & $\begin{array}{l}\text { Altered } \\
\text { mental } \\
\text { status }\end{array}$ & Nausea or vomiting \\
\hline $\mathrm{I}$ & $23 /$ male & $\mathrm{T}$ & - & + & + & + & - & + \\
\hline 2 & $27 /$ male & $P, F$ & + & + & + & - & + & + \\
\hline Our case & $25 /$ female & $\mathrm{P}, \mathrm{O}$ & - & + & + & + & + & + \\
\hline
\end{tabular}

Abbreviations: $T$, temporal; $P$, parietal; $F$, frontal; $O$, occipital. 
however, with timely diagnosis effective treatment is available by treating the underlying cause.

\section{Disclosure}

The authors declare that there is no conflict of interests regarding the publication of this paper. Additionally, no outside funding was utilized in this study.

\section{References}

1. Sadek AR, Waters RJ, Sparrow OC. Posterior reversible encephalopathy syndrome: a case following reversible cerebral vasoconstriction syndrome masquerading as subarachnoid hemorrhage. Acta Neurochir (Wien). 2012;154(3):413-416.

2. Lee VH, Wijdicks EF, Manno EM, and Rabinstein AA. Clinical spectrum of reversible posterior leukoencephalopathy syndrome. Arch Neurol. 2008; 65(2):205-210.

3. Loar RW, Patterson MC, O'Leary PW, Driscoll DJ, Johnson JN. Posterior reversible encephalopathy syndrome and hemorrhage associated with tacrolimus in a pediatric heart transplantation recipient. Pediatr Transplant. 2013;17(2):E67-E70.

4. Pereira PR, Pinho J, Rodrigues M, et al. Clinical, imagiological and etiological spectrum of posterior reversible encephalopathy syndrome. Arg Neuropsiquiatr. 2015;73(1):36-40.
5. Landtblom AM, Fridriksson S, Boivie J, Hillman J, Johansson G, Johansson I. Sudden onset headache: a prospective study of features, incidence and causes. Cephalalgia. 2002;22(5):354-360.

6. Ducros A, Boukobza M, Porcher R, Sarov M, Valade D, Bousser MG. The clinical and radiological spectrum of reversible cerebral vasoconstriction syndrome. A prospective series of 67 patients. Brain. 2007;130(Pt 12):3091-3101.

7. Nabi Z, Al Korbi L, Ghailani M, Nadri Q, Abdelsalem M, Al Baqumi M. Reversible posterior leukoencephalopathy syndrome in a patient of FSGS with heavy proteinuria. Ren Fail. 2010;32(7):892-894.

8. de Oliveira RA, Fechine LM, Neto FC, Nicodemus JM, Silva GB Jr, Silva LS. Posterior reversible encephalopathy syndrome (PRES) induced by cyclosporine use in a patient with collapsing focal glomerulosclerosis. Int Urol Nephrol. 2008;40(4):1095-1098.

9. Stott VL, Hurrell MA, Anderson TJ. Reversible posterior leukoencephalopathy syndrome a misnomer reviewed. Intern Med J. 2005; 35(2):83-90.

10. Hefzy HM, Bartynski WS, Boardman JF, Lacomis D. Hemorrhage in posterior reversible encephalopathy syndrome: imaging and clinical features. AJNR Am J Neuroradiol. 2009;30(7):1371-1379.

11. Kuroda H, Kashimura H, Murakami T, Endo H, Mase T, Ogasawara K. Early onset of PRES in a patient with a subarachnoid haemorrhage due to a ruptured intracranial aneurysm. Br J Neurosurg. 2014; 28(6):785-786.
Neuropsychiatric Disease and Treatment

\section{Publish your work in this journal}

Neuropsychiatric Disease and Treatment is an international, peerreviewed journal of clinical therapeutics and pharmacology focusing on concise rapid reporting of clinical or pre-clinical studies on a range of neuropsychiatric and neurological disorders. This journal is indexed on PubMed Central, the 'PsycINFO' database and CAS,

\section{Dovepress}

and is the official journal of The International Neuropsychiatric Association (INA). The manuscript management system is completely online and includes a very quick and fair peer-review system, which is all easy to use. Visit http://www.dovepress.com/testimonials.php to read real quotes from published authors. 